extending their proper terms of reference, and he did not wish the establishment of the curriculum study groups to lead towards centralized control of the curriculum or towards misdirected central influence on it. If a schools council were set up, however, he would wish it to be more than a purely advisory body and that it should possess complete autonomy in all matters which did not fall within the Minister's statutory powers and responsibilities. With regard to the size of any such council, Sir Edward insisted that education in Britain was a shared service, and accordingly such a council must bring together the Ministry and local authorities and the teachers. $\mathrm{He}$ hoped that the council would also include not only representatives of those concerned with the day-to-day work of education in the schools, but also some who could point out lines of research on issues which might be overlooked by others, members who were competent to challenge the Ministry and Britain's traditional day-to-day approaches to the kind of research which was most needed.

The proposals mentioned by Mr. Wiley were sent to the Minister for Science by the heads of departments and institutes of education of universities in England and Wales. They refer to the danger of a patchwork of shortterm projects and base their proposals on the organization of the existing Research Councils responsible to Lord Hailsham.

\title{
TRANSLATIONS OF LITERATURE ON NUCLEAR ENERGY
}

T HE European Atomic Energy Community (Euratom), the United States Atomic Energy Commission, and the United Kingdom Atomic Energy Authority have agreed to pool their efforts in order to collect and disseminate information on translations of nuclear litera. ture, in particular of documents originally written in languages unfamiliar to the Western reader. An information office 'Transatom' has been set up at the headquarters of Euratom in Brussels for the collection of data concerning translations of interest, and a monthly guide to nuclear literature in translation, Transatom Bulletin, compiled by Euratom is published by the Elsevier Publishing Company, Amsterdam. The Bulletin is in English and provides a unique survey of translations into English, French, German and Italian, of articles, monographs, books, reports, etc., in the field of nuclear science and technology originally published in the non-Western world. Precise bibliographical data of the original Russian, East European, Japanese and Chinese documents are included in the Bulletin, together with the addresses of the translation agencies which can supply copies of the translations listed and the conditions of availability of the translations. Certain journals receive cover-to-cover translation and a separate list of these is printed in every issue of the Bulletin. The various entries in the Bulletin are classified under fourteen headings, covering general and specialized areas of science and technology in which nuclear energy is either fundamental or has found some application.

A list of translations in preparation, but yet not completed, which may be of special value to many organizations so as to avoid duplication of effort and unneces. sary expense, is an added feature of the Bulletin. Both author and source indexes are given in every issue of the Bulletin, and cumulative quarterly indexes are included in the Nos. 3,6 and 9 issues, with an annual cumulative author and source index in the final (No. 12) issue of the year and volume. The Bulletin is now in its third year of publication.

A new publication of Euratom, Euratom-Information *, is to be published bi-monthly. The research undertaken by Euratom which is now five years old is beginning to give rise to a rapidly increasing number of reports, at present at about one a day, and the new publication will act primarily as a periodical catalogue of the reports. The contents of the first issue of Euratom-Information is divided into five sections. The first contains a list of 104 scientific and technical publications; the second 33 patents; the third the research contracts signed. by the Euratom Commission up to December 31, 1962; the fourth details of the research activities which the Commission plans to carry out as from January 1, 1963, and in which individuals and organizations within Euratom can collaborate; and finally, a statement of the EuratomUnited States of America joint research and development programme. In the first section, where the publication referred to is not in English, the foreign language summary together with the translation of both the title and summary are given. Details of how to obtain copies of the reports and publications listed are included.

\section{S. WEINTROUB}

* Euratom-Information, Vol. 1, No. 1 (May 1963). (A publication of the Furopean Atomic Energy Community.) Pp. 1-81. Published at twomonthly intervals. (Düsseldorf: Handelsblatt, G.m.b.H., Kreuze-Strasse 21, 1963.) Annual subscription 15 dollars.

\section{REFLECTED LIGHT MICROSCOPY}

$\mathrm{T}$ HE quantitative methods which can be applied to the study of opaque minerals (natural and synthetic) under the polarizing microscope are the measurement of reflectivity, of rotation properties, and of micro-indentation hardness. Recent advances in these methods have brought them to the point where it is believed that they can be generally applied in a way similar to the use of optical methods in the identification of transparent minerals.

With the view of disseminating knowledge of these methods as widely as possible, a small committee of British mineralogists was set up to organize an international Summer School. With the aid of a generous grant from the Scientific Affairs Division of the North Atlantic Treaty Organization, an advanced study course was held during June 23-July 2 in the Department of Mineralogy and Petrology, Cambridge. There were thirty-one members, including eight observers, drawn from twenty-three different countries; all except two of those in the observer category were mineralogists engaged in academic work.

The basic techniques and theory were covered in seven lectures and practical demonstrations, after which the members divided into two sections (ore minerals and coal petrology) for a further six lectures followed by practical work in either section. Each member had a total of thirty hours of practical work, and in addition there were three colloquia. Throughout the course emphasis was placed on the practical aspects of quantitative measurements, and this was made possible by the generous loan of equipment by several firms. Much of the apparatus, which included reflecting-polarizing microscopes, monochromators, photometers and micro-indentation hardness testers, was of recent design, and the opportunity was taken of obtaining comments from the members on the equipment.

Further information about this Summer School can be obtained from the secretary, Dr. N. F. M. Henry, Department of Mineralogy and Petrology, Cambridge. 